Published: Miao, C., Humphrey, R. H., \& Qian, S. (2017). Are the emotionally intelligent good citizens or counterproductive? A meta-analysis of emotional intelligence and its relationships with organizational citizenship behavior and counterproductive work behavior. Personality and Individual Differences. 16, 144-156. http://dx.doi.org/10.1016/j.paid.2017.04.015

\title{
Are the Emotionally Intelligent Good Citizens or Counterproductive? A Meta-Analysis of Emotional Intelligence and its Relationships with Organizational Citizenship Behavior and Counterproductive Work Behavior
}

\begin{abstract}
This research project examines whether emotional intelligence (EI) is related to organizational citizenship behavior (OCB) and counterproductive work behavior (CWB). A key question concerns the degree to which EI is related to OCB and CWB after controlling for other established predictors. The study uses meta-analytical summaries of existing research (for EIOCB, $\mathrm{k}=68, \mathrm{~N}=16,386$; for $\mathrm{EI}-\mathrm{CWB}, \mathrm{k}=17, \mathrm{~N}=3,914)$. It uses meta-analytical controls to obtain the best estimates of effect sizes, incremental validity, and relative importance. This metaanalysis found that EI is positively associated with $\mathrm{OCB}$ and negatively related to CWB. When controlling for ability measures of EI, the Big Five personality measures, general self-efficacy, cognitive intelligence, and self-rated performance, both self-report measures of EI and mixed competency measures of EI show incremental validity and relative importance in predicting OCB and CWB. An analysis of self-report EI found that the effects of EI on OCB and CWB are stronger in health care and service industries than in industries where emotional labor demands
\end{abstract}


are lower. The results imply that organizations can increase OCB and reduce CWB by recruiting employees high in EI and by training employees in emotional competencies.

Keywords: emotional intelligence; organizational citizenship behavior; counterproductive work behavior; meta-analysis; emotional labor. 


\section{Are the Emotionally Intelligent Good Citizens or Counterproductive? A Meta-Analysis of Emotional Intelligence and its Relationships with Organizational Citizenship Behavior and Counterproductive Work Behavior}

For almost a century, management scholars and practitioners held Weber's view that emotions in the workplace interfered with administrative rationality, and that emotions led to favoritism and caused conflict and other undesirable behaviors. Ashforth and Humphrey (1995) quoted Weber's famous statement (translated and reprinted in 1968) that bureaucracy prospers ... the more it is "dehumanized," the more completely it succeeds in eliminating from official business love, hatred, and all purely personal, irrational, and emotional elements which escape calculation.

$$
\text { (Weber, 1968, p.75). }
$$

As this quote illustrates, Weber equated emotions with irrational behavior, the sort of behavior that contributes to counterproductive work behavior (CWB). However, Ashforth and Humphrey argued that emotions can be functional for organizations, and that emotions are essential to organizational commitment and positive morale. Instead of interfering with decision-making, they maintained that emotions can spur creativity and improve decision-making when properly managed and stimulated.

The negative view of emotions began to change with the publication of Goleman's (1995) influential book called Emotional Intelligence: Why it can matter more than IQ. According to this perspective, employees and others low on emotional intelligence (EI) may experience anger, panic, fear, jealousy, and other negative emotions when confronted with problems, and react in antisocial and other dysfunctional ways. In contrast, people high on emotional intelligence regulate their emotions to excel at work and in life, and perform empathic prosocial behaviors. 
This view suggests that EI would be an important variable predicting prosocial organizational citizenship behavior (OCB) and CWB.

Goleman's (1995) book aroused considerable controversy because of his claim that EI was often more important than IQ in determining success at school and at work (see also Cherniss, 2001), and this controversy continues to this day. Although numerous studies have shown that EI is related to various positive outcomes, critics have argued that these positive relationships would disappear once the studies controlled for cognitive intelligence and established personality measures such as the Big Five (for a review of these criticisms, see Walter, Cole, \& Humphrey, 2011, who acknowledge that the requests to demonstrate incremental validity are reasonable). Effect sizes for variables are best established by metaanalyses that summarize the effect sizes across various studies. Meta-analyses are also the best way to determine incremental validity and relative importance because they use the best estimates for the effect sizes of the different variables. No prior meta-analyses have examined the relationships between EI and OCB and CWB. Thus, a crucial question addressed by this meta-analysis concerns the ability of EI measures to predict OCB and CWB when controlling for other established predictors.

There is also considerable controversy about the nature of EI and how to measure it (Ashkanasy \& Daus, 2005). Whereas some view EI as a form of intelligence that should be measured by "ability" items (e.g., Salovey \& Mayer, 1990), others view EI more in trait terms (Petrides, 2009a, 2009b; Petrides \& Furnham, 2003; Smith, Saklofskea, \& Yan, 2015). According to one popular definition of trait EI, it is "a constellation of emotion-related selfperceptions and dispositions located at the lower levels of personality hierarchies" (Vernon, Petrides, Bratko, \& Schermer, 2008, page 635, definition based on Petrides, Pita, \& Kokkinaki, 
2007). A third view treats EI as a set of mixed traits and competencies (e.g., Bar-On, 2002;

Boyatzis, Brizz, \& Godwin, 2011; Emmerling \& Boyatzis, 2012). Thus, this meta-analyses aims

to cast light on this issue by examining how well ability, trait, and mixed measures do in terms of incremental validity and relative importance. A finding that the three types of measures have different associations with OCB and CWB would further support the belief that these measures are conceptually distinct and represent different concepts.

Alongside with task performance, OCB has emerged as one of the most important variables of interest to organizational psychologists and practitioners. In his early conceptualization of OCB, Organ (1988, p. 4) maintained that "OCB represents individual behavior that is discretionary, not directly or explicitly recognized by the formal reward system, and in the aggregate promotes the efficient and effective functioning of the organization." In an important revision of his definition of OCB, Organ (1997, p. 95) stated that OCB is "performance that supports the social and psychological environment in which task performance takes place." This increased emphasis on the social and psychological environment suggests that emotional intelligence (EI), a trait or competency related to social skills and psychological knowledge (Goleman, 1995, Goleman, Boyatzis, \& McKee, 2013; Salovey \& Mayer, 1990; Petrides, 2009a, 2009b; Petrides \& Furnham, 2003; Schutte et al., 2007; Van Rooy \& Viswesvaran, 2004), should also play a role in performing OCB as well as CWB.

To sum up, this meta-analysis aims to address several key issues. First, it is essential to understand whether EI is positively associated with the performance of OCB, and negatively related to CWB, and the overall size of these relationships. Second, because there are three major ways to conceptualize and measure EI, it is important to know how the three methods compare in their ability to predict OCB and CWB. Third, citizenship behaviors and counterproductive 
behaviors can be directed either towards individuals or the organization, so it is useful to know if the target influences the size of the EI - OCB/CWB relationships. Fourth, it is vital to know the relative importance of EI as a predictor when examining other personality traits, such as the Big Five, general self-efficacy, and cognitive intelligence. Fifth, it is useful to know if the type of work performed (i.e., industry type) influences the relationships between EI and OCB/CWB.

\section{Theory and Hypotheses}

\subsection{The importance of EI}

A considerable number of scholars and researchers have developed measures of EI. Ashkanasy and Daus (2005, p. 441) brought clarity to the field by classifying the scales into three streams. These have become known as the stream 1 ability measures, the stream 2 selfreports, and the stream 3 mixed competencies models. This classification system has been used in prior meta-analysis research, reviews, and textbooks (Humphrey, 2013; Miao et al., 2016a, 2016b; O’Boyle et al., 2011; Walter et al., 2011). O'Boyle and his colleagues demonstrated support for the classification system by showing that the three streams have different correlations with the Big Five personality factors and with cognitive intelligence, thus demonstrating their distinctness. They found that although the 3 streams had similar correlations with job performance, they differed in their incremental validity regarding job performance. Their study supports the view that ability measures are empirically as well as conceptually distinct from trait measures. This view is supported by Joseph and Newman (2010), who found that performance based measures (i.e., ability measures) had corrected correlations of .12 with self-report measures and .23 with mixed EI measures. Consequently, it would be useful to see if ability 
measures, self-report measures, and mixed measures also differ in their incremental validity with regard to $\mathrm{OCB}$ and $\mathrm{CWB}$.

The three streams differ considerably in their conceptualization of emotional intelligence. Ability measures, such as the MSCEIT V2.0, were devised to meet standard criteria for intelligence measures, with objective right and wrong answers. This matches their definition of EI as a type of intelligence (Mayer et al., 2003). In contrast, many investigators in the self-report stream 2 category conceptualize EI in trait terms (Petrides, 2009a, 2009b; Petrides \& Furnham, 2003; Smith, Saklofskea, \& Yan, 2015). They believe that EI should be assessed the way most personality traits are measured by using self-reports, and they have argued that people's internal emotional states can best be measured by self-reports. These researchers have created their own scales. Petrides, Pita, and Kokkinaki (2007) used factor analysis to investigate the interrelationships among the TEIQue and other personality constructs. They concluded that the factor analysis supports the "conceptualization of trait EI as a lower-order construct that comprehensively encompasses the emotion-related facets of personality" (Petrides et al., 2007, p. 287). Equally important, this study found that the TEIQue yielded incremental predictability over the Big Five when examining life satisfaction, rumination, rational coping, detached coping, and emotional coping. Incremental predictability for a short form of the TEIQue has also been demonstrated (Siegling, Vesely, Petrides, \& Saklofske, 2015). According to a meta-analysis, the TEIQue is not redundant with other personality measures and has incremental predictability when predicting important life outcomes (burnout and depression, alcohol abuse, academic achievement, and life and job satisfaction) (Andrei, Siegling, Aloe, Baldaro, \& Petrides, 2016). Like the stream 2 self-reports, the stream 3 mixed competency measures use self-reports (BarOn, 2002; Boyatzis, Brizz, \& Godwin, 2011; Emmerling \& Boyatzis, 2012); however, they are 
considered "mixed competencies" because they include a greater number of dimensions and subscales. Because of this greater breadth, it is possible that the mixed competency measures will show greater ability to predict outcome measures.

A number of recent reviews and meta-analyses have found that EI is related to a variety of important outcomes. Meta-analyses have confirmed that EI is positively related to job performance (Van Rooy \& Viswesvaran, 2004) after controlling for cognitive intelligence and the Big Five (O’Boyle et al., 2011; Joseph \& Newman, 2010). A meta-analysis has also confirmed that EI shows incremental validity and relative importance when predicting job satisfaction, organizational commitment, and turnover intentions (Miao, Humphrey, \& Qian, 2016a). Meta-analyses have also shown that EI is related to physical, mental and psychosomatic health (Martins, Ramalho, \& Morin, 2010; Schutte et al, 2007). Reviews of the literature have concluded that EI is positively related to leadership emergence, the performance of effective leadership behaviors (such as transformational leadership), and overall leadership effectiveness (Walter, Cole, \& Humphrey, 2011). Moreover, leaders score higher on EI than do followers (Siegling, Nielsen, \& Petrides, 2014a; Siegling, Sfeir, \& Smyth, 2014b). Per a recent metaanalysis, leaders' EI positively relates to subordinates' job satisfaction even when controlling for personality and cognitive intelligence (Miao, Humphrey, \& Qian, 2016b).

Although meta-analyses have supported the validity of EI regarding job performance, job satisfaction, affective commitment, turnover intentions, mental and physical health, life satisfaction, and leadership (see above), no meta-analyses have been done to examine the effects of EI on either OCB or CWB. Because of the importance of both OCB and CWB to the workplace, it is important to understand the role that EI might play regarding OCB and CWB. Scholars have argued forcefully that EI measures need to demonstrate incremental validity over 
measures of cognitive intelligence and Big Five personality measures (Antonakis, Ashkanasy, \& Dasborough, 2009). As of yet, the incremental validity of EI with regard to OCB or CWB has not been established, and individual studies are not sufficient to overcome scepticism about EI because individual studies could always be atypical. A meta-analysis that yields the best estimates for effect sizes is needed to firmly establish incremental validity and relative importance for the EI to OCB and CWB relationships.

Lingering scepticism about the incremental validity of EI is largely due to its overlap with measures of the Big Five personality traits (Antonakis, et al., 2009). According to this view, the overlap shows that the EI measures are redundant and suggest that they are merely alternative measures of the Big Five. In contrast, O'Boyle et al. (2011) argued that some overlap is to be expected and could even be evidence of support for the validity of EI. For example, their finding that ability EI correlates moderately (corrected correlation $=.315$ ) with cognitive intelligence supports the conceptualization of ability EI as a form of intelligence. Likewise, the moderate correlations between self-report EI measures and personality measures support the view that stream 2 self-report EI measures represent traits. The positive correlations between self-report EI and extroversion (corrected correlation .318) and conscientiousness (.377) are examples of convergent validity and support the theory that self-report EI measures aspects of social effectiveness.

O’Boyle et al.'s (2011) findings can also been seen as consistent with the view that trait EI captures the "emotion-related facets of personality" (Petrides et al., 2007, p. 287). Thus the overlap represents how EI, a lower-order personality construct, measures the emotional side of personality. A large scale meta-analysis has examined the relationship between ability and trait EI with a "general factor of personality" that underlies the Big Five measures (van der Linden, et 
al., 2017). This study found that the general factor of personality correlates .28 with ability measures and .85 with trait EI. The authors conclude that trait EI may be synonymous with the general factor of personality and may represent the social effectiveness dimension of personality. In addition, they noted that EI measures have shown incremental validity over measures of the Big Five. This could be because trait EI measures assess aspects of social effectiveness not measured by the Big Five, or in other ways better represent the general factor of personality. In light of their findings, we believe it is crucial to examine whether EI measures show incremental validity with regard to the Big Five and OCB and CWB.

\subsection{The importance of $O C B$ and $C W B$}

OCB and CWB have emerged as two of the most important constructs in organizational psychology. OCB and CWB affect the success or failure of an organization and have a sizeable impact on the welfare of individuals in the organizations (Gonzalez-Mulé, Mount, \& Oh, 2014). OCB improves organizational effectiveness (Koys, 2001; Podsakoff \& MacKenzie, 1997) and a wide variety of important outcomes. A meta-analysis has provided compelling evidence that OCB improves both organizational and individual outcomes (Podsakoff, Whiting, Podsakoff, \& Blume, 2009). With regard to organizational performance, OCB improves productivity, efficiency, customer satisfaction, and reduces costs and unit-level turnover. Regarding individual outcomes, performing citizenship behaviors aids employees in obtaining rewards and higher performance evaluations, and reduces their turnover intentions, actual turnover, and absenteeism. For task performance the meta-analysis found a substantial relationship between task performance and citizenship behavior directed towards individuals (corrected correlation of .47) and towards the organization (corrected correlation of .54). Because OCB has such strong effects 
on performance, it is important to understand the factors that lead employees to perform citizenship behaviors.

CWB also has important effects on organizations. A recent meta-analysis has found that CWB is negatively related to job satisfaction, and positively related to conflict (Berry, Carpenter $\&$ Barratt, 2012). Work stressors are often assumed to be a major cause of CWB; however, a five wave longitudinal study found reciprocal effects between work stressors and counterproductive behavior because counterproductive behavior can lead to work stress (Meier \& Spector, 2013). People whose personality traits predispose them to commit CWB may find themselves increasing their own work stress. Prior studies have shown that openness, agreeableness, and conscientiousness are negatively related to performing counterproductive behaviors (Berry et al., 2012). Because negative emotions play a key role in motivating CWB according to the stressoremotion model of CWB (Spector \& Fox, 2002), EI, which involves the ability to manage and control emotions, should be another important personality trait related (negatively) to CWB. EI may also play a role in reducing counterproductive work behavior (CWB), the evil twin to OCB. As defined by Spector and Fox (2002, p. 271), "CWB is behavior intended to hurt the organization or other members of the organization." CWB may consist of a variety of different counterproductive behaviors, including physical or verbal aggression against other organizational members, sabotage of equipment or physical facilities, theft, and purposely doing work poorly or slowly (Bennett \& Robinson, 2000).

\subsection{EI - OCB/CWB Relationships}

Prior meta-analyses (e.g., O’Boyle et al., 2011; Van Rooy \& Viswesvaran, 2004) only focused on how EI predicts the task performance component of job performance, whereas job 
performance consists of three related, yet distinct, components: task performance, OCB, and CWB (Berry, Ones, \& Sackett, 2007; Rotundo \& Sackett, 2002). As such, whether prior findings that EI predicts task performance generalize to OCB and CWB remains an open question.

EI may motivate employees to perform OCB in large part because EI is related to empathy. Goleman and his colleagues avow that empathy is "the fundamental competence of social awareness" and "the sine qua non of all social effectiveness in working life" (Goleman, Boyatzis, \& McKee, 2013, p.50). A considerable body of literature has related empathy to prosocial behaviour. Borman and his colleagues (Borman, Penner, Allen, \& Motowidlo, 2001) tested dispositional predictors of OCB, including measures of the Big Five, and they found that other-oriented empathy had the highest zero-order correlation with OCB. Researchers have examined empathy's effects on prosocial behavior, testing what has become called the empathyaltruism hypothesis (Batson, Eklund, Chermok, Hoyt, \& Ortiz 2007; Paciello, Fida, Cerniglia, Tramontano, \& Cole, 2013). The empathy-altruism hypthesis has been confirmed by metaanalytic summaries of the research using both surveys and lab studies (Eisenberg \& Miller, 1987). Studies have shown that EI scales predict empathy (Kellett, Humphrey, \& Sleeth, 2002; 2006).

EI may also increase OCB because it improves the quality and effectiveness of helping behaviors. Kolb and Boyatzis (1970) classified helpers into 3 categories: effective helpers, ineffective helpers, and nonhelpers. People high on EI might be both more motivated to help and have greater ability to do so because of their keen understanding of human nature. In a theory piece, Dudley and Cortina (2008) argued that knowledge and skill, not just motivation, are essential to performing OCB. Chief among the skills they mention are ones related to EI, 
including emotional knowledge, self-insight, social perception, perspective taking, emotion perception and management, and emotional support.

EI may reduce CWB in particular because it helps employees cope with the negative feelings and frustrations that normal work problems often create. Regulation of emotions, both with regard to oneself and others, is a key part of EI. As the stressor-emotion model of CWB (Spector \& Fox, 2002) depicts, these negative emotions are a key cause of CWB. People high on EI should be able to handle typical problems without undue negative emotions, in contrast, employees low on EI may not be able to handle the stress and act out in counterproductive ways.

Individual primary studies have found that EI is positively related to OCB and negatively related to CWB. With regard to OCB, Prentice, Chen, \& King (2013) found that EI was positively related to OCB among customer service employees. At the other end of the employment spectrum, executives high on EI are also more likely to perform altruistic OCB (Antony, 2013; Cichy, Kim, \& Cha, 2009; Jain, 2012). Studies using a cross section of employees have found that EI is positively related to OCB and negatively related to CWB (e.g., Greenidge, Devonish, \& Alleyne, 2014). Even professionals may engage in CWB, and De Clercq, Bouckenooghe, Raja, and Matsyborska (2014) found that EI was negatively related to organizational deviance (i.e., CWB) and positively related to engagement among a sample of informational technology professionals (see also Akhtar, Boustani, Tsivrikos, \& ChamorroPremuzic, 2015).

Based upon the above literature review, we derive the following set of hypotheses regarding the main effects of EI on OCB and CWB.

Hypothesis 1. All three streams of EI ([a]stream 1 ability measures, [b]stream 2 self-reports, and [c]stream 3 mixed models) will be positively related to OCB. 
Hypothesis 2. All three streams of EI ([a]stream 1 ability measures, [b]stream 2 self-reports, and [c]stream 3 mixed models) will be negatively related to CWB.

\subsection{Incremental Ability and Relative Importance}

In addition to testing these main effects, to improve the methodological rigor of the study, it is important to establish that EI also predicts OCB and CWB after controlling for other wellestablished covariates that overlap with EI (Miao et al., 2016a, 2016b; O'Boyle et al., 2011). In this study, we control for cognitive ability, the Big Five (conscientiousness, op, general selfefficacy, and self-rated performance. In addition, we also account for stream 1 ability EI when we assess the incremental validity and relative importance of stream 2 self-report EI and stream 3 mixed competency EI. Stream 2 self-report EI and stream 3 mixed EI should capture the construct domain of stream 1 ability EI. Thus including stream 1 ability measures alongside the other control variables in the regression models of stream 2 and 3 EI should increase the bar for stream 2 and 3 EI to demonstrate incremental validity and relative importance and thus make our results more conservative. Thus, we offer the following hypotheses.

Hypothesis 3. All three streams of EI ([a]stream 1 ability measures, [b]stream 2 self-reports, and [c]stream 3 mixed models) will show incremental validity and relative importance in predicting OCB when controlling for the Big Five, cognitive intelligence, general self-efficacy, and selfrated job performance.

Hypothesis 4. All three streams of EI ([a]stream 1 ability measures, [b]stream 2 self-reports, and [c]stream 3 mixed models) will show incremental validity and relative importance in predicting CWB when controlling for the Big Five, cognitive intelligence, general self-efficacy, and selfrated job performance.

\subsection{Moderators}


The three streams have important theoretical distinctions because of the way they are measured and conceptualized. Stream 1 ability models are measured the way cognitive intelligence is measured with objective right and wrong items; thus, they have the highest correlation with cognitive intelligence and the lowest with the Big Five personality factors (O'Boyle et al., 2011), and they operate in some ways like cognitive intelligence measures do. This matches the conceptualization of it as a type of intelligence.

In contrast, the stream 2 self-report measures are sometimes referred to as trait measures of EI because they are measured the way traits are often measured, and some proponents argue that EI has trait like properties. These advocates claim that ability measures tap semantic knowledge, but do not as closely measure actual behavior as the self-report measure do. In support of this view, the O'Boyle et al. (2011) meta-analysis found that the stream 2 measures correlated more with the Big Five traits, less with cognitive intelligence, and had more incremental predicted ability with regard to job performance than the stream 1 measures did.

Finally, the stream 3 mixed competencies models draw upon a wider set of skills than do the other two streams, and are conceptualized as learnable skills that can be developed over time. Because of their greater domain of constructs included, these measures have the greatest relative weights and incremental predictability of the three streams when it comes to job performance (O’Boyle et al., 2011) and health outcomes (Martins et al., 2010).

Nontask performance, such as OCB and CWB, are less influenced by cognitive ability, and are more influenced by one's personality traits, because ability only best predicts technical proficiency related criteria (i.e., task performance) whereas personality traits better predict criteria related to interpersonal behaviors, teamwork, and contextual performance (i.e., OCB and CWB) (Gonzalez-Mulé et al., 2014). Stream 3 mixed competency EI has highest overlap with 
Big Five personality measures, and personality measures are better predictors of OCB and CWB than are cognitive intelligence measures. On the other hand, stream 1 ability EI has the lowest overlap with the Big Five (yet highest overlap with cognitive ability), which suggests it would have the lowest predictive validity of $\mathrm{OCB}$ and CWB. For these reasons, we offer the following hypotheses.

Hypothesis 5. Stream 3 mixed models will show the strongest positive relationships with OCB, stream 2 self-reports the second strongest, and stream 1 ability models will show the weakest relationships.

Hypothesis 6. Stream 3 mixed models will show the strongest negative relationships with CWB, stream 2 self-reports the second strongest, and stream 1 ability models will show the weakest relationships.

The context-based approach to EI suggests that the validity of EI may be contingent on contexts (Farh, Seo, \& Tesluk, 2012). Work contexts contain salient trait-relevant cues (i.e., emotion-based cues) that are likely to activate the expression of EI and thus may strengthen its association with some workplace outcomes. Industry is a contextual moderator that may condition the relationships between EI and OCB/CWB (Choi, Oh, \& Colbert, 2015; Farh et al., 2012). Our moderator hypotheses are couched in trait activation theory. This theory indicates that traits are more predictive of outcomes when a context has trait-relevant cues because these cues will activate the expression of one's psychological traits and stimulate one to behave in a manner that corresponds to contextual cues (Farh et al., 2012; Tett \& Guterman, 2000).

There are some meta-analytic distributions that have too few samples to produce robust results for moderators, so these are not tested (i.e., stream 1 ability EI - OCB, stream 1 ability EI - CWB, and stream 3 mixed competency EI - CWB distributions). We framed the moderator 
hypotheses developed later in this paper for the situations where there were a suitably large number of samples to provide an adequate test of moderation effects.

Emotional labor is defined as "the management of feeling to create a publicly observable facial and bodily display" (Hochschild, 1983, p.7). Emotional labor jobs generally involve face to face or voice to voice interactions with the public, generating an emotional state in another person, and a degree of employer's control over employees' emotional activities (Hochschild, 1983). Emotional labor requires one to display proper emotion (i.e., adhering to a display rule) and to regulate either feelings or expressions to accomplish organizational goals (Ashforth \& Humphrey, 1993; Grandey, 2000). Literature reviews and meta-analytic findings have demonstrated that emotional labor is associated with employee well-being, job satisfaction, and job performance (Hulsheger \& Schewe, 2011; Humphrey, Ashforth, \& Diefendorff, 2015).

We suspect that the relationship between EI and OCB/CWB is moderated by work contexts. We predict that when a job involves high customer/interpersonal interaction (i.e., high emotional labor demand), EI becomes even more relevant. A meta-analysis has found that EI is related to emotional labor and that people high on EI are more likely to use the most effective form of emotional labor (Wang, Seibert, \& Boles, 2011). Emotional labor often requires employees to portray positive emotions and suppress the expression of negative emotions. These job demands may stimulate an even higher use of EI to display OCB and suppress CWB (Jain, Malhotra, \& Guan, 2012). EI helps employees recognize situational demands to perform emotional labor (Brotheridge, 2006). Thus employees high on EI may be more likely to recognize their customers' concerns and to voluntarily help them with their problems. Employees performing emotional labor may require high levels of EI activation to suppress their negative emotions and remain polite to moody customers who are acting rudely. 
Many studies we identified did not report the exact nature of the jobs held by research subjects. Therefore, we could not directly code the emotional labor demand of each sample. We instead used the industry where the sample for each study comes from (see details of coding in method section) as a proxy for emotional labor demand of jobs. We used healthcare and service industries as a proxy for jobs high in emotional labor demand. Accordingly, we hypothesized: Hypothesis 7. The relationships are stronger in healthcare and service industries than in other industries (a) between stream 2 self-reports and OCB, (b) between stream 3 mixed models and OCB, and (c) between stream 2 self-reports and CWB.

Using self-reported ratings on both $\mathrm{EI}$ and $\mathrm{OCB} / \mathrm{CWB}$ may make the results susceptible to common method bias because research findings indicated that if the same respondent reports on the scales of both a predictor and a criterion, self-report bias may create artifactual covariance between a predictor and a criterion, thus leading to a bias in effect size estimates (Podsakoff, MacKenzie, \& Podsakoff, 2012). The bias in effect sizes caused by common rater effect can be due to consistency motif, illusory correlations, leniency biases, and transient mood state (Podsakoff et al., 2012). To minimize common method bias, Podsakoff et al. recommended obtaining responses on a predictor and a criterion from different sources. Given that the use of different sources of ratings should minimize common method bias, we expect that the relationships between $\mathrm{EI}$ and $\mathrm{OCB} / \mathrm{CWB}$ will turn weaker when observer ratings of $\mathrm{OCB} / \mathrm{CWB}$ are used.

Hypothesis 8. The relationships will become weaker when observer ratings of OCB and CWB are used (a) between stream 2 self-reports and OCB, (b) between stream 3 mixed models and OCB, and (c) between stream 2 self-reports and CWB. 
Some prior meta-analyses have shown scale-based moderation (e.g., Banks et al., 2014; Berry et al., 2007; Judge, Thoresen, Bono, \& Patton, 2001); in accordance with prior research, we examine whether EI, OCB, and CWB scales moderate the EI - OCB/CWB relationships. We argued that popularly used and more established scales may produce different effect sizes relative to newer and less established ones (Banks et al., 2014). We presented the following exploratory research question.

Research Question 1. Do the relationships (a) between stream 2 self-reports and OCB and (b) between stream 3 mixed models and OCB and (c) between stream 2 self-reports and CWB vary across different measures of EI, OCB, and CWB?

It is also worth knowing if the target of OCB/CWB influences the relationships with EI. Scholars have argued that it is important to know if OCB/CWB directed towards individuals is distinct from that directed towards organizations in terms of their relationships with other variables, and meta-analyses routinely examine this issue because of its importance (LePine, Erez, \& Johnson, 2002; Ng, Lam, \& Feldman, 2016). Due to these reasons, we offer the following exploratory research question.

Research Question 2. Do the relationships between all three streams of EI and OCB and all three streams of EI and CWB vary by the target (individual vs. organizational) of the behavior?

\section{Method}

\subsection{Literature Search}

We used several search strategies to maximize the chance of locating all pertinent studies. We employed a set of keywords (and several variations of them) to search for relevant articles, such as emotional intelligence, emotional ability, emotional competency, organizational 
citizenship behavior, contextual performance, extra-role behavior, counterproductive work behavior, deviant behavior, deviance, and aggression.

First, we searched electronic databases, such as ABI/INFORM, EBSCO Host (e.g., Academic Search Complete and Business Source Complete), Google, Google Scholar, ProQuest Dissertations and Theses, PsycNET (e.g., PsycInfo and PsycArticles), ScienceDirect, and Social Science Citation Index. Second, although our electronic database search had already captured nearly all relevant journals, we still did manual search of relevant journals to ensure the comprehensiveness of our electronic database search. Our manual search included journals such as Academy of Management Journal, Administrative Science Quarterly, Journal of Applied Psychology, Journal of Management, Journal of Management Studies, Journal of Organizational Behavior, Journal of Personality and Social Psychology, Journal of Vocational Behavior, Organizational Behavior and Human Decision Processes, Organization Science, Personality and Individual Differences, Personnel Psychology, and Psychological Science. Third, we searched all relevant major management conferences, such as Academy of Management, Southern Management Association, and Society for Industrial and Organizational Psychology. We contacted EI scholars to request unpublished studies, correlation matrices, and raw data. Our initial search returned 1,151 studies.

\subsection{Inclusion Criteria}

We set the criteria as listed below to sort the articles we identified in our initial search. We considered a study eligible for inclusion in our meta-analysis if it met the following standards. First, primary studies must be empirical and quantitative. All qualitative studies were eliminated from our database. Second, primary studies had to report a correlation coefficient for the relationship between $\mathrm{EI}$ and $\mathrm{OCB} / \mathrm{CWB}$. When primary studies failed to report correlation 
coefficients, enough statistics needed to be reported in such studies to allow us to convert them into effect sizes (Lipsey and Wilson's [2001] and Peterson and Brown's [2005] methods were used to perform effect size conversions). Third, primary studies had to be based on real employee samples. We excluded the studies using non-employee samples (e.g., student samples). Fourth, primary studies must employ scales designed to measure EI. We excluded the studies using proxy measures of EI (e.g., self-monitoring scales). After we applied the above criteria to winnow the articles, it resulted in 68 samples for EI - OCB relationship and 17 samples for EI CWB relationship. A reference list of the studies included in the present meta-analysis was uploaded as online supplemental materials.

\subsection{Coding Procedures}

We followed three streams of EI categorization proposed by Ashkanasy and Daus (2005) to code EI stream number of each study. We coded industry of each study in accordance with North American Industry Classification System (NAICS) into health care and service industries versus others. We coded the rating method of OCB and CWB into self-report and observerreport methods. Our coding for interpersonal and organizational dimensions of OCB and CWB were consistent with prior meta-analysis papers on these topics (e.g., Berry et al., 2007; Chiaburu et al., 2011; Dalal, 2005). The coding processes of EI, OCB, and CWB scales were straightforward and did not involve any judgment calls. In line with prior meta-analytic reviews (e.g., Crook et al., 2011), we combined facet-level effect sizes to generate a single effect size when a study provided multiple facet-level effect sizes of a construct.

Two coders were involved in coding and independently coded each study. The initial coding agreement was $96 \%$. Coding disagreement was handled via discussion. When two coders cannot reach consensus through discussion another author of this paper was asked to participate 
in the discussion to resolve any remaining coding discrepancies. All coding disagreements were resolved and a $100 \%$ consensus was reached.

\subsection{Meta-Analytic Procedures}

We performed psychometric meta-analysis following the procedures developed by Hunter and Schmidt (2004). Statistical artifacts can exert a systematic downward bias effect on effect sizes and one type of statistical artifacts is measurement error (Hunter \& Schmidt, 2004). We corrected for measurement errors in both independent and dependent variables for each individual effect size.

We found that some primary studies did not provide reliability coefficients. Therefore, we imputed the missing reliability for both independent and dependent variables by employing the mean of reliabilities of the studies that provided reliability coefficients (Hunter \& Schmidt, 2004). Since three streams of EI are related yet distinct from each other (O'Boyle et al., 2011), we imputed reliability for each EI stream by employing the average reliability for each particular EI stream (Imputed reliabilities for stream 1 ability $\mathrm{EI}=.76$, stream 2 self-report $\mathrm{EI}=.86$, and stream 3 mixed competency $E I=.81$ ). The imputed reliabilities for dependent variables are .82 for OCB, .77 for OCB-I (OCB directed toward individuals), .74 for OCB-O (OCB directed toward the organization), .86 for CWB-I (CWB directed toward individuals), and .88 for CWB$\mathrm{O}$ (CWB directed toward the organization). There is no missing reliability for overall CWB.

We reported corrected sample-size-weighted mean correlation $(\hat{\rho})$ as population mean correlation estimate. We computed corrected $95 \%$ confidence intervals to assess the statistical significance of effect sizes. When corrected $95 \%$ confidence intervals do not contain zero the effect sizes are said to be statistically significant. We conducted moderator analyses by following Hunter and Schmidt's (1990) approach (i.e., z-test). This test examines the statistical significance 
of between-group effect size difference. We calculated $\operatorname{Var}_{\text {art }} \%$ and $80 \%$ credibility intervals to evaluate the potential presence of moderators. $\operatorname{Var}_{a r t} \%$ refers to the percent of the variance in $\hat{\rho}$ explained by statistical artifacts. Moderators may exist if statistical artifacts account for less than $75 \%$ of the variance in the meta-analytic correlations (Hunter \& Schmidt, 2004). We also provided corrected $80 \%$ credibility intervals because a wide $80 \%$ credibility interval may suggest the potential presence of moderators (Whitener, 1990).

\subsection{Hierarchical Multiple Regression Analyses and Relative Weight Analyses}

Hierarchical multiple regression analysis can examine incremental validity and beta weights obtained from this analysis can be compared in terms of rank-order. Nonetheless, relative contribution of each predictor to the total variance explained cannot be derived from this analysis (Johnson \& LeBreton, 2004; O’Boyle et al., 2011; Tonidandel \& LeBreton, 2011). Relative importance of each predictor in the model can be determined based on beta weights or zero-order correlations only when predictors are uncorrelated (O'Boyle et al., 2011). These indices (i.e., beta weights or zero-order correlations) may produce misleading information regarding relative importance of predictors when predictors are correlated (Johnson \& LeBreton, 2004). We conducted relative weight analyses to tackle this methodological issue. Relative weight analyses yield more precise estimates of the relative importance of each predictor in predicting a dependent variable in a multivariate model where predictors are correlated. For instance, a weight of .6 for a predictor is twice as critical as another predictor having a weight of .3 in a model where these two predictors are correlated.

We applied the criteria proposed by O'Boyle et al. (2011) to determine the magnitude of relative importance of each predictor. O'Boyle and his colleagues employed $R^{2}$ values of .01, .09 , and .25 as small, medium, and large relative importance based on the work of Cohen (1988). 
They cautioned that using Cohen's standard is a conservative approach because Cohen's standard is developed for bivariate relations but not multivariate models. This means a medium effect at the bivariate level may be small or non-significant when other predictors are included in a model.

We built meta-analytically derived corrected correlation matrices and utilized IBM SPSS Statistics 22 to conduct hierarchical multiple regression analyses and relative weight analyses. In addition to the effect sizes derived from the present study, we also utilized the corrected effect sizes from prior meta-analysis papers to complete the input correlation matrices (see Table S1 in supplemental materials) required for aforesaid analyses. We calculated and used harmonic mean sample size because sample sizes varied across the cells in the correlation matrices. Harmonic mean sample size yields more conservative estimates in that less weight is assigned to large samples (Colquitt, Scott, \& LePine, 2007).

\section{Results}

\subsection{Main and Moderator Effects}

Table 1 displays the results of the relationship between EI and OCB/CWB based on psychometric meta-analysis. The relationship between stream 1 ability measures of EI and OCB $(k=7, N=1,022)$ was positive and statistically significant $(\hat{\rho}=.17)$ because corrected $95 \%$ confidence interval ranged from .11 to .23 and excluded zero. The relationships between the other two streams of EI and OCB $(\hat{\rho}=.57$ for stream 2 self-report EI and $\hat{\rho}=.48$ for stream 3 mixed competency EI) demonstrated positive and statistically significant results as well. Thus hypothesis 1 is supported for all three streams. With respect to CWB, the relationships between stream 2 self-reports and 3 mixed competency EI and CWB were negative and significant $(\hat{\rho}=-$ .38 for stream 2 EI and $\hat{\rho}=-.42$ for stream $3 \mathrm{EI})$. Yet, the relationship between stream 1 ability 
EI and CWB was not significant $(\hat{\rho}=.01)$. In light of these results, we conclude Hypothesis 2 is supported only for stream 2 self-reports and stream 3 mixed competency models.

We observed that there were considerable variations across effect sizes for stream 2 selfreports $\mathrm{EI}$ - OCB, stream 3 mixed competency EI - OCB, and stream 2 self-reports EI - CWB distributions because far less than $75 \%$ of the variance in $\hat{\rho}\left(\operatorname{Var}_{a r t} \%\right)$ for these distributions was accounted for by statistical artifacts. This satisfied Hunter and Schmidt's $75 \%$ rule for the potential presence of moderators. We further checked the corrected $80 \%$ credibility intervals of these distributions and found them to be wide, further affirming our conclusion that effect size distributions were heterogeneous for these meta-analytic distributions. In sum, performing further moderator analyses was justified.

\section{Insert Table 1 about here}

The results of moderator analyses are shown in the last column of Table 1 . We conducted a series of z-tests to assess the statistical significance of between-group differences (i.e., moderator effects). Results demonstrated that stream 1 ability EI has the lowest association with OCB compared to stream 2 self-reports and stream 3 mixed competency EI (stream 2 self-reports EI versus stream 1 ability EI, $\Delta \hat{\rho}=.40, p<.05$; stream 3 mixed competency EI versus stream 1 ability EI, $\Delta \hat{\rho}=.31, p<.05)$. The difference between stream 2 self-reports EI and stream 3 mixed competency EI in their relation to OCB is not statistically significant $(\Delta \hat{\rho}=.09)$. Thus hypothesis 5 is supported only for the differences with regard to stream 1 ability EI. As for CWB, we found that stream 1 ability EI demonstrated the lowest relation with CWB relative to stream 2 self-reports and stream 3 mixed competency EI (stream 2 self-reports EI versus stream 1 ability EI, $\Delta \hat{\rho}=-.39, p<.05 ;$ stream 3 mixed competency EI versus stream 1 ability EI, $\Delta \hat{\rho}=$ $-.43, p<.05)$. Nevertheless, the difference between stream 2 self-reports EI and stream 3 mixed 
competency EI in their association with CWB is not statistically significant either $(\Delta \hat{\rho}=-.04)$.

Hence, we concluded that hypothesis 6 is supported only for the differences with respect to stream 1 ability EI.

Hypothesis 7 states that relationships are stronger in healthcare and service industries than in other industries (a) between stream 2 self-reports and OCB, (b) between stream 3 mixed models and OCB, and (c) between stream 2 self-reports and CWB. This hypothesis was supported only for the stream 2 measures. Hypothesis 8 tests whether the relationships will become weaker when observer ratings of OCB and CWB are used (a) between stream 2 selfreports and $\mathrm{OCB}$, (b) between stream 3 mixed models and $\mathrm{OCB}$, and (c) between stream 2 selfreports and CWB. Hypothesis 8 was not supported, thus indicating that self and observer relationships are equally strong.

Research Question 1 asks, do the relationships (a) between stream 2 self-reports and OCB and (b) between stream 3 mixed models and OCB and (c) between stream 2 self-reports and CWB vary across different measures of EI, OCB, and CWB? We found that the relationships do not vary across EI measures (within streams) but vary across OCB and CWB measures. Research Question 2 asks, do the relationships between all three streams of EI and OCB and all three streams of EI and CWB vary by the target (individual vs. organizational) of the behavior? We found that the strength of the relationships is equally strong across targets, so the relationships do not vary. For clarity of reporting, we tabulated the results for all hypotheses testing in Table 2.

\section{Insert Table 2 about here}

\subsection{Incremental Validity and Relative Weight Analyses}

To assess whether EI improves the prediction of OCB and CWB, EI should explain variance above and beyond what has already been explained by well-established predictors (i.e., 
the Big Five personality traits, cognitive ability, general self-efficacy, and self-rated job performance) and demonstrate relative importance in the presence of these established predictors. Table 3 and Table 4 show the results of incremental validity analysis based on hierarchical multiple regression analysis. When the dependent variable is OCB (see Table 3), the first model demonstrates that control variables (i.e., cognitive ability, personality traits, general self-efficacy, and self-rated job performance) explain 15\% $(p<.001)$ of the variance in OCB. When the dependent variable is CWB (see Table 4), control variables account for $16 \%(p<.001)$ of the variance in CWB. The second, third, and fourth models display the incremental validity of each EI stream in the presence of all control variables in predicting OCB and CWB.

When dependent variable is OCB (see Table 3), the second model demonstrates that stream 1 ability EI yields no incremental validity $(p=n s)$ in the presence of control variables. Yet, the third and fourth models indicate that both stream 2 self-reports EI and stream 3 mixed competency EI yield an additional 18\% $(p<.001)$ and $47 \%(p<.001)$ of variance above and beyond control variables respectively. Thus, with regard to incremental validity in predicting OCB, hypothesis 3 is supported only for stream 2 self-reports and stream 3 mixed competency EI.

When the dependent variable is CWB (see Table 4), the second model denotes that stream 1 ability EI contributes no incremental validity $(p=n s)$ in the presence of control variables. However, the third and fourth models demonstrate that both stream 2 self-reports EI and stream 3 mixed competency EI contribute an additional $4 \%(p<.001)$ and $32 \%(p<.001)$ of variance above and beyond control variables respectively. Thus, hypothesis 4 is not supported for stream 1 ability EI, but is supported for stream 2 self-reports and stream 3 mixed competency EI with regard to incremental validity in predicting CWB. 


\section{Insert Table 3 about here \\ Insert Table 4 about here}

We conducted relative weight analyses to determine the relative importance of each predictor in predicting $\mathrm{OCB}$ and $\mathrm{CWB}$. Table 3 and Table 4 show the results of relative weight analyses in the last two columns of each model.

When the dependent variable is OCB (see Table 3), stream 1 ability EI contributes $7.9 \%$ of the explained variance with a $R^{2}$ contribution of .012 in model 2 . It met the threshold for a small relative importance. Stream 1 ability EI ranks fifth out of nine predictors in its relative importance in predicting OCB in model 2. Both stream 2 self-reports EI and stream 3 mixed competency EI demonstrated relative importance compared to control variables. Stream 2 selfreports EI contributed $57.4 \%$ of the explained variance with a $R^{2}$ contribution of .189 . Stream 2 self-reports EI met the criterion of a medium relative importance and ranks first out of nine predictors in its relative importance in predicting OCB. Similarly, stream 3 mixed competency EI contributed $53.2 \%$ of the explained variance with a $R^{2}$ contribution of .328 in model 4 . Stream 3 mixed competency EI met the criterion of a large relative importance and ranks first out of nine predictors in its relative importance. Thus, when it comes to relative importance, hypothesis 3 is supported for all three streams of EI.

We repeated the same procedure above when the dependent variable is CWB (see Table 4). We found that streams 1, 2, 3 EI demonstrated $7.3 \%\left(R^{2}=.012\right), 24.4 \%\left(R^{2}=.049\right)$, and $41.6 \%\left(R^{2}=.201\right)$ of the explained variance. Streams $1,2,3$ EI displayed small, small, and medium relative importance and ranked sixth, first, and first out of nine predictors in its relative importance respectively. Thus hypothesis 4 is supported when considering the relative importance of all three streams of EI. 


\section{Discussion and Conclusions}

We provided the first meta-analytic review to investigate the relationships between EI and $\mathrm{OCB} / \mathrm{CWB}$. Our general conclusion is that emotionally savvy individuals are likely to be good organizational soldiers who are prosocial and helpful, and that they refrain from engaging in deviant activities. We found that all three streams of EI are positively related to OCB, although only streams 2 self-reports EI and stream 3 mixed competency EI are negatively related to CWB. Our findings support the view that emotionally savvy individuals can recognize and understand others' feelings and perceive others' need for help and have the skills necessary to help. In addition, emotionally intelligent employees have better comprehension of organizational norms and rules so that they can exhibit behaviors that show compliance with and support for the organization (Carmeli \& Josman, 2006). Emotionally intelligent individuals also refrain from engaging in deviant activities that may hinder the accomplishment of organizational goals. Our findings are in line with the stressor-emotion model of CWB (Spector \& Fox, 2002). Emotionally intelligent individuals can harness their EI to maintain positive emotions and to regulate negative emotions; this allows them to experience higher job satisfaction and positive state affect, and these positive feelings constrain CWB and stimulate OCB.

With regard to the controversy over the incremental validity of EI measures (Antonakis, et al., 2009), our results firmly demonstrate that self-report and mixed EI have incremental validity when including measures of ability EI, the Big Five, cognitive intelligence, general selfefficacy, and self-rated performance when predicting OCB and CWB. The sizes of the incremental increases are substantial; adding self-report EI to the equation for predicting OCB more than doubles the r-square, from .15 to .33; adding mixed EI quadruples it to .63. For CWB, r-square increases from .16 to .20 when adding self-report EI, and triples to .48 when adding 
mixed EI. A recent meta-analysis also found that self-report and mixed EI demonstrated incremental validity when controlling for cognitive intelligence and the Big Five when predicting job satisfaction, organizational commitment, and turnover intentions (Miao et al., 2016a). For example, this meta-analysis found that adding self-report EI doubled the r-square for turnover intentions, from .07 to .14. Two other meta-analyses have found incremental validity for selfreport and mixed EI measures when controlling for cognitive intelligence and the Big Five when predicting job performance (O’Boyle et al., 2011; Joseph \& Newman, 2010). In light of all of these consistent findings, we believe it is time to lay this controversy to rest and to acknowledge that self-report and mixed EI measures add substantial incremental validity.

We found that stream 2 self-reports EI - OCB and stream 2 self-reports EI - CWB relationships are stronger in health care and service industries than in other industries. This indicates that individuals are more likely to employ their EI to display OCB and constrain CWB in health care and service industries where emotional labor demand is high. This is because emotional labor calls for the use of EI and increases EI's relevance in a work context (Johnson \& Spector, 2007). This finding also supports trait activation theory (Tett \& Burnett, 2000) and context-based approaches to EI (Farh et al., 2012) because when a work context contains traitrelevant cues (i.e., emotion-based cues in health care and service industries), it triggers one's expression/use of EI and they are prompted to act in ways to attend to these cues, thus influencing job behaviors (i.e., OCB and CWB).

Observer ratings of OCB/CWB did not weaken the relationships between EI and OCB/CWB. In line with Spector's (2006) research on common method variance (CMV), our findings indicate that CMV does not seem to be a universal inflator of the associations between EI and OCB/CWB. Thus, we may not assume prima facie that CMV is problematic across all 
situations. Our finding also echoes recent research findings (Berry et al., 2012; Carpenter, Berry, \& Houston, 2014) that observer-reports of OCB and CWB resemble self-reports of them because observer-reports of OCB and CWB demonstrate very similar nomological networks with selfreports and display negligible incremental variance.

We did not detect any moderating effect of EI scales within each stream of EI, meaning that the effect sizes for $\mathrm{EI}-\mathrm{OCB} / \mathrm{CWB}$ relationships remain nearly identical across different $\mathrm{EI}$ scales within each EI stream. This indicates that different EI scales within each EI stream may tap similar construct domains of EI that are predictive of OCB and CWB, thus affirming the three streams of EI classification proposed by Ashkanasy and Daus (2005). Their classification of three EI streams have been further confirmed by our finding showing that stream 1 ability EI has weaker relationship with OCB and CWB than stream 2 self-reports and stream 3 mixed competency EI. This is due to stream 1 ability EI's low correlation with personality, and because personality measures are relatively stronger predictors of OCB and CWB than cognitive measures. Our findings support the view that trait measures of EI are both conceptually and empirically different from ability measures (Petrides, et al., 2007; Vernon, et al., 2008).

We identified the moderating effects of both OCB and CWB scales because EI OCB/CWB relationships vary across these scales. This finding coincides with the findings from prior meta-analytic reviews (Berry et al., 2007; Podsakoff et al., 2000) that different OCB and CWB measures may capture different forms/types of OCB and CWB behaviors, which may lead to difference in effect sizes.

With regard to our second exploratory research question, we did not find any differences in the EI to OCB/CWB relationships by the target of the behavior (individual vs. organizational). Our finding demonstrates that EI has a nearly identical effect on OCB-O and CWB-O relative to 
OCB-I and CWB-I. Thus both organization-directed and individually directed OCB and CWB are noticeably affected by EI. For example, one should be emotionally intelligent when speaking up to his/her supervisor (i.e., employee voice - one type of OCB-O) because voice behavior may be mistakenly viewed as complaints or harsh criticisms by supervisors and one may risk damaging the relationship with his/her boss if voice is not performed in an emotionally intelligent way. Similarly, CWB-O, such as sabotage, should be considerably influenced by EI because sabotage is typically provoked by negative emotions and emotionally intelligent individuals can control their negative emotions to curb CWB-O (Spector \& Fox, 2002). Our results are also consistent with other meta-analyses that have found that OCB and CWB have similar relationships to personality traits (LePine et al., 2002).

With regard to limitations and avenues for future research, some meta-analytic distributions had a small number of samples, making some results susceptible to second-order sampling error. This explains why some moderator analyses are inconsistent across EI streams. This problem is particularly relevant for EI - CWB distributions, which have fewer samples than EI - OCB distributions. Moderator analysis in meta-analysis is a low power test (Steel \& Kammeyer-Mueller, 2002). Therefore, after we stratified our samples into different subgroups, the results of moderation may not be significant if there are small numbers of samples in each subgroup. Small sample sizes are also why we cannot test moderators for stream 1 ability EI OCB, stream 1 ability EI - CWB, and stream 3 mixed competency EI - CWB. We encourage readers to exercise caution when interpreting the results of moderator analyses with small numbers of samples.

Second, our meta-analysis was dominated by cross-sectional studies; as such, we are unable to rule out the possibility of reverse causality (or reciprocal causation). To cope with this 
limitation, future research should use longitudinal designs and perform advanced analyses, such as latent growth modeling, to make robust causal inferences.

Third, although we identified and tested a set of moderators, it is noted that there are still many meta-analytic distributions that have substantial heterogeneity in effect sizes' variance according to Hunter and Schmidt $75 \%$ rule. Our results provide a roadmap for future research to explore more moderators beyond what we found in the present study.

Fourth, more research needs to be done to examine the relationships between EI and the general factor of personality (van der Linden, et al., 2017). The large relative importance for trait EI supports the position that trait EI may be synonymous with a general factor of personality for social effectiveness. Because this would represent a major change in our understanding of personality, this assertion needs further replication and testing. If supported, it would demonstrate the central role of EI to overall personality.

Fifth, our results have implications for a variety of other research areas. Given the positive relationships between $\mathrm{EI}$ and $\mathrm{OCB}$, it makes senses to investigate how EI relates to variables such as trust and justice. Are employees high on EI more likely to trust others? Or does high EI increase the ability to know when to trust others and when to doubt them? Do leaders high on EI treat their followers and subordinates more fairly? Are top leaders who are high in EI more likely to support corporate social responsibility programs? What about contingent rewards? Are leaders high in EI more or less likely to use contingent rewards? And how do high EI followers respond to contingent rewards? How does EI determine how employees and leaders use job resources and on their ability to gain job resources for themselves and their followers? In terms of practical implications, we found that all three streams of EI (stream 1 ability EI, stream 2 self-reports EI, and stream 3 mixed competency EI) demonstrated relative 
importance in predicting OCB and CWB after cognitive ability, big five personality traits, general self-efficacy, and self-rated job performance were accounted for. Both stream 2 selfreports and stream 3 mixed competency EI augment the prediction of OCB and CWB beyond aforesaid well-established predictors of OCB and CWB. Given that OCB and CWB play a critical role in influencing performance at team and organizational levels (Dunlop \& Lee, 2004;

Podsakoff et al., 2009), we encourage practitioners to incorporate an EI test during their selection process to recruit potentially helpful and altruistic individuals and screen out hostile and harmful individuals. We also note that EI is more predictive of OCB and CWB in health care and service industries where jobs are emotion-based and involve frequent management of emotions (e.g., the jobs involve frequent interpersonal interaction). Overall, the relative importance analysis demonstrates that self-report and mixed EI measures are by far the most important personality predictors of OCB and CWB, accounting for over half of the explained variance in OCB by themselves, and ranked number 1 when predicting CWB. Thus, these EI measures should be the first choice among personality measures for both practitioners and researchers.

\section{References}

Akhtar, R., Boustani, L., Tsivrikos, D., \& Chamorro-Premuzic, T. (2015). The engageable personality: Personality and trait EI as predictors of work engagement. Personality and Individual Differences, 73, 44-49.

Andrei, F., Siegling, A. B., Aloe, A. M., Baldaro, B., \& Petrides, K. V. (2016). The incremental validity of the Trait Emotional Intelligence Questionnaire (TEIQue): A systematic review and meta-analysis. Journal of Personality Assessment, 98, 261-276.

Antonakis, J., Ashkanasy, N. M., \& Dasborough, M. T. (2009). Does leadership need emotional intelligence? The Leadership Quarterly, 20: 247-261. 
Antony, J. M. (2013). The influence of emotional intelligence on organizational commitment and organizational citizenship behavior. International Journal of Social Science \& Interdisciplinary Research, 2(3), 110-115.

Ashforth, B. E., \& Humphrey, R. H. (1993). Emotional labor in service roles: The influence of identity. Academy of Management Review, 18, 88-115.

Ashforth, B. E., \& Humphrey, R. H. (1995). Emotion in the Workplace: A Reappraisal. Human Relations, 48(2), 97-125.

Ashkanasy, N. M., \& Daus, C. S. (2005). Rumors of the death of emotional intelligence in organizational behavior are vastly exaggerated. Journal of Organizational Behavior, 26, $441-452$.

Banks, G. C., Batchelor, J. H., Seers, A., O'Boyle, E. H., Pollack, J. M., \& Gower, K. (2014). What does team-member exchange bring to the party? A meta-analytic review of team and leader social exchange. Journal of Organizational Behavior, 35, 273-295.

Bar-On, R. (2002). Bar-On EQ-i technical manual. Toronto: Multi-Health Systems.

Batson, C. D., Eklund, J. H., Chermok, V. L., Hoyt, J. L., \& Ortiz, B. G. (2007). An additional antecedent of empathic concern: Valuing the welfare of the person in need. Journal of Personality and Social Psychology, 93, 65-74.

Bennett, R. J., \& Robinson, S. L. (2000). Development of a measure of workplace deviance. Journal of Applied Psychology, 85, 349-360.

Berry, C. M., Carpenter, N. C., \& Barratt, C. L. (2012). Do other-reports of counterproductive work behavior provide an incremental contribution over self-reports? A meta-analytic comparison. Journal of Applied Psychology, 97, 613-636.

Berry, C. M., Ones, D. S., \& Sackett, P. R. (2007). Interpersonal deviance, organizational deviance, and their common correlates: A review and meta-analysis. Journal of Applied Psychology, 92, 410-424.

Borman, W. C., Penner, L. A., Allen, T. D., \& Motowidlo, S. J. (2001). Personality predictors of citizenship performance. International Journal of Selection and Assessment, 9, 52-69. 
Boyatzis, R., Brizz, T., \& Godwin, L. (2011). The effect of religious leaders' emotional and social competencies on improving parish vibrancy. Journal of Leadership \& Organizational Studies, 18, 192-206.

Brotheridge, C. M. (2006). The role of emotional intelligence and other individual difference variables in predicting emotional labor relative to situational demands. Psicothema, 18, $139-144$.

Carmeli, A., \& Josman, Z. E. (2006). The relationship among emotional intelligence, task performance, and organizational citizenship behaviors. Human Performance, 19, 403419.

Carpenter, N. C., Berry, C. M., \& Houston, L. (2014). A meta-analytic comparison of selfreported and other-reported organizational citizenship behavior. Journal of Organizational Behavior, 35, 547-574.

Cherniss, C. (2001). Emotional intelligence and organizational effectiveness. In C. Cherniss \& D. Goleman (Eds.), The emotionally intelligent workplace (pp. 3-12). San Francisco: Jossey-Bass.

Choi, D., Oh, I. S., \& Colbert, A. E. (2015). Understanding organizational commitment: A metaanalytic examination of the roles of the five-factor model of personality and culture. Journal of Applied Psychology, 100, 1542-1567.

Cichy, R. F., Kim, S. H., \& Cha, J. (2009). The relationship between emotional intelligence and contextual performance: Application to automated and vending service industry executives. Journal of Human Resources in Hospitality \& Tourism, 8(2), 170-183.

Clarke, N., \& Mahadi, N. (2017). The significance of mutual recognition respect in mediating the relationships between trait emotional intelligence, affective commitment and job satisfaction. Personality and Individual Differences, 105, 129-134.

Colquitt, J. A., Scott, B. A., \& LePine, J. A. (2007). Trust, trustworthiness, and trust propensity: A meta-analytic test of their unique relationships with risk taking and job performance. Journal of Applied Psychology, 92, 909-927. 
Crook, T. R., Todd, S. Y., Combs, J. G., Woehr, D. J., \& Ketchen, D. J. (2011). Does human capital matter? A meta-analysis of the relationship between human capital and firm performance. Journal of Applied Psychology, 96, 443-456.

De Clercq, D., Bouckenooghe, D., Raja, U., \& Matsyborska, G. (2014). Unpacking the goal congruence-organizational deviance relationship: The roles of work engagement and emotional intelligence. Journal of Business Ethics, 124(4), 695-711.

Dudley, N. M., \& Cortina, J. M. (2008). Knowledge and skills that facilitate the personal support dimension of citizenship. Journal of Applied Psychology, 93, 1249.

Dunlop, P. D., \& Lee, K. (2004). Workplace deviance, organizational citizenship behavior, and business unit performance: The bad apples do spoil the whole barrel. Journal of Organizational Behavior, 25, 67-80.

Eisenberg, N., \& Miller, P. A. (1987). The relation of empathy to prosocial and related behaviors. Psychological Bulletin, 101, 91-119.

Emmerling, R. J., \& Boyatzis, R. E. (2012). Emotional and social intelligence competencies: Cross cultural implications. Cross Cultural Management: An International Journal, 19, 4-18.

Farh, C. I., Seo, M. G., \& Tesluk, P. E. (2012). Emotional intelligence, teamwork effectiveness, and job performance: The moderating role of job context. Journal of Applied Psychology, 97, 890-900.

Goleman, D. (1995). Emotional intelligence: Why it can matter more than IQ. New York, NY: Bantam Books.

Goleman, D., Boyatzis, R., \& McKee, A. (2013). Primal leadership: Unleashing the power of emotional intelligence. Harvard Business Press.

Gonzalez-Mulé, E., Mount, M. K., \& Oh, I. S. (2014). A meta-analysis of the relationship between general mental ability and nontask performance. Journal of Applied Psychology, 99, 1222-1243. 
Grandey, A. A. (2000). Emotion regulation in the workplace: A new way to conceptualize emotional labor. Journal of Occupational Health Psychology, 5, 95-110.

Greenidge, D., Devonish, D., \& Alleyne, P. (2014). The relationship between ability-based emotional intelligence and contextual performance and counterproductive work behaviors: A test of the mediating effects of job satisfaction. Human Performance, 27(3), $225-242$.

Jain, A. K. (2012). Moderating effect of impression management on the relationship of emotional intelligence and organizational citizenship behavior. Journal of Behavioral and Applied Management, 13(2), 86.

Jain, A. K., Malhotra, N. K., \& Guan, C. (2012). Positive and negative affectivity as mediators of volunteerism and service-oriented citizenship behavior and customer loyalty. Psychology \& Marketing, 29, 1004-1017.

Joseph, D. L., \& Newman, D. A. (2010). Emotional intelligence: an integrative meta-analysis and cascading model. Journal of Applied Psychology, 95, 1, 54 -78.

Judge, T. A., Thoresen, C. J., Bono, J. E., \& Patton, G. K. (2001). The job satisfaction-job performance relationship: A qualitative and quantitative review. Psychological Bulletin, 127, 376-407.

Kellett, J. B., Humphrey, R. H., \& Sleeth, R. G. (2002). Empathy and complex task performance: Two routes to leadership. The Leadership Quarterly, 13, 523-544.

Kellett, J. B., Humphrey, R. H., \& Sleeth, R. G. (2006). Empathy and the emergence of task and relations leaders. The Leadership Quarterly, 17, 146-162.

Kellett, J. B., Humphrey, R. H., \& Sleeth, R. G. (2009). Career development, collective efficacy, and individual task performance. Career Development International, 14, 534-546.

Kolb, D. A., \& Boyatzis, R. E. (1970). On the dynamics of the helping relationship. The Journal of Applied Behavioral Science, 6, 267-289.

Koys, D. J. (2001). The effects of employee satisfaction, organizational citizenship behavior, and turnover on organizational effectiveness: A unit-level, longitudinal study. Personnel Psychology, 54, 101-114. 
Hochschild, A. R. (1983). The managed heart: Commercialization of human feelings. University of California Press. CA: Berkeley.

Hülsheger, U. R., \& Schewe, A. F. (2011). On the costs and benefits of emotional labor: A metaanalysis of three decades of research. Journal of Occupational Health Psychology, 16, 361-389.

Humphrey, R. H. (2013). Effective Leadership: Theory, cases, and applications. Los Angeles, CA: Sage.

Humphrey, R. H., Ashforth, B. E., \& Diefendorff, J. M. (2015). The bright side of emotional labor. Journal of Organizational Behavior, 36, 749-769.

Hunter, J. E., \& Schmidt, F. L. (1990). Methods of meta-analysis: Correcting error and bias in research findings. Beverly Hills, CA: Sage.

Hunter, J. E., \& Schmidt, F. L. (2004). Methods of meta-analysis: Correcting error and bias in research findings. Newbury Park, CA: Sage.

Johnson, H. A. M., \& Spector, P. E. (2007). Service with a smile: Do emotional intelligence, gender, and autonomy moderate the emotional labor process? Journal of Occupational Health Psychology, 12, 319.

Judge, T. A., \& Kammeyer-Mueller, J. D. (2008). Affect, satisfaction, and performance. In N. M. Ashkanasy \& C. L. Cooper (Eds.), Research companion to emotion in organizations (Chapter 8, pp. 136-151). Cheltenham, UK: Edward Elgar.

LePine, J. A., Erez, A., \& Johnson, D. E. (2002). The nature and dimensionality of organizational citizenship behavior: A critical review and meta-analysis. Journal of Applied Psychology, 87, 52-65.

Lipsey, M. W., \& Wilson, D. B. (2001). Practical meta-analysis. Sage Publications: Thousand Oaks, CA, 2001.

Martins, A., Ramalho, N., \& Morin, E. (2010). A comprehensive meta-analysis of the relationship between emotional intelligence and health. Personality and Individual Differences, 49, 554-564. 
Miao, C., Humphrey, R. H., \& Qian, S. (2016a). A meta-analysis of emotional intelligence and work attitudes. Journal of Occupational and Organizational Psychology.

Miao, C., Humphrey, R. H., \& Qian, S. (2016b). Leader emotional intelligence and subordinate job satisfaction: A meta-analysis of main, mediator, and moderator effects. Personality and Individual Differences, 102, 13-24.

Ng, T. W., Lam, S. S., \& Feldman, D. C. (2016). Organizational citizenship behavior and counterproductive work behavior: Do males and females differ? Journal of Vocational Behavior, 93, 11-32.

O’Boyle, E. H., Humphrey, R. H., Pollack, J. M., Hawver, T. H., \& Story, P. A. (2011). The relation between emotional intelligence and job performance: A meta-analysis. Journal of Organizational Behavior, 32, 788-818.

Organ, D. W. (1997). Organizational citizenship behavior: It's construct clean-up time. Human Performance, 10, 85-97.

Paciello, M., Fida, R., Cerniglia, L., Tramontano, C., \& Cole, E. (2013). High cost helping scenario: The role of empathy, prosocial reasoning and moral disengagement on helping behavior. Personality and Individual Differences, 55, 3-7.

Petrides, K. V. (2009a). Psychometric properties of the Trait Emotional Intelligence Questionnaire (TEIQue). In C. Stough, D. H. Saklofske, \& J. D. A. Parker (Eds.), Assessing emotional intelligence: Theory, research, and applications. (pp. 85-101). New York, NY: Springer Science.

Petrides, K. V. (2009b). Technical manual for the Trait Emotional Intelligence Questionnaire (TEIQue). London, England: London Psychometric Laboratory.

Petrides, K. V., \& Furnham, A. (2003). Trait emotional intelligence: Behavioral validation in two studies of emotion recognition and reactivity to mood induction. European Journal of Personality, 17, 39-57.

Petrides, K. V., Pita, R., \& Kokkinaki, F. (2007). The location of trait emotional intelligence in personality factor space. British Journal of Psychology, 98, 273-289. 
Podsakoff, P. M., \& MacKenzie, S. B. (1997). Impact of organizational citizenship behavior on organizational performance: A review and suggestions for future research. Human Performance, 10, 133-151.

Podsakoff, P. M., MacKenzie, S. B., Paine, J. B., \& Bachrach, D. G. (2000). Organizational citizenship behaviors: A critical review of the theoretical and empirical literature and suggestions for future research. Journal of Management, 26, 513-563.

Podsakoff, P. M., MacKenzie, S. B., \& Podsakoff, N. P. (2012). Sources of method bias in social science research and recommendations on how to control it. Annual Review of Psychology, 63, 539-569.

Podsakoff, N. P., Whiting, S. W., Podsakoff, P. M., \& Blume, B. D. (2009). Individual-and organizational-level consequences of organizational citizenship behaviors: A metaanalysis. Journal of Applied Psychology, 94, 122-141.

Peterson, R. A., \& Brown, S. P. (2005). On the use of beta coefficients in meta-analysis. Journal of Applied Psychology, 90, 175-181.

Prentice, C., Chen, P. J., \& King, B. (2013). Employee performance outcomes and burnout following the presentation-of-self in customer-service contexts. International Journal of Hospitality Management, 35, 225-236.

Rotundo, M., \& Sackett, P. R. (2002). The relative importance of task, citizenship, and counterproductive performance to global ratings of job performance: A policy-capturing approach. Journal of Applied Psychology, 87, 66-80.

Salovey, P., \& Mayer, J. D. (1990). Emotional intelligence. Imagination, Cognition and Personality, 9, 185-211.

Schutte, N. S., Malouff, J. M., Thorsteinsson, E. B., Bhullar, N., \& Rooke, S. E. (2007). A metaanalytic investigation of the relationship between emotional intelligence and health. Personality and Individual Differences, 42, 921-933.

Siegling, A. B., Sfeir, M., \& Smyth, H. J., (2014a). Measured and self-estimated trait emotional intelligence in a UK sample of managers. Personality and Individual Differences 65, 5964. 
Siegling, A. B., Nielsen, C., Petrides, K. V. (2014b). Trait emotional intelligence and leadership in a European multinational company. Personality and Individual Differences, 65, 65-68.

Siegling, A. B., Vesely, A. K., Petrides, K. V., \& Saklofske, D. H. (2015). Incremental Validity of the Trait Emotional Intelligence Questionnaire-Short Form (TEIQue-SF). Journal of Personality Assessment, 97, 525-535.

Smith, M. M., Saklofskea, D. H., \& Yan, G. (2015). Perfectionism, trait emotional intelligence, and psychological outcomes. Personality and Individual Differences, 85,155-158.

Spector, P. E., \& Fox, S. (2002). An emotion-centered model of voluntary work behavior: Some parallels between counterproductive work behavior and organizational citizenship behavior. Human Resource Management Review, 12, 269-292.

Spector, P. E. (2006). Method variance in organizational research truth or urban legend? Organizational Research Methods, 9, 221-232.

Steel, P. D., \& Kammeyer-Mueller, J. D. (2002). Comparing meta-analytic moderator estimation techniques under realistic conditions. Journal of Applied Psychology, 87, 96 - 111.

Tett, R. P., \& Guterman, H. A. (2000). Situation trait relevance, trait expression, and crosssituational consistency: Testing a principle of trait activation. Journal of Research in Personality, 34, 397-423.

Tonidandel, S., \& LeBreton, J. M. (2011). Relative importance analysis: A useful supplement to regression analysis. Journal of Business and Psychology, 26, 1-9.

van der Linden, D., Pekaar, K. A., Bakker, A. B., Schermer, J. A., Vernon, P. A., Dunkel, C. S., $\&$ Petrides, K. V. (2017). Overlap between the general factor of personality and emotional intelligence: A meta-analysis. Psychological Bulletin, 143(1), 3652. http://dx.doi.org/10.1037/bul0000078

Van Rooy, D. L., \& Viswesvaran, C. (2004). Emotional intelligence: A meta-analytic investigation of predictive validity and nomological net. Journal of Vocational Behavior, 65, 71-95.

Vernon, P.A., Petrides, K.V., Bratko, D., \& Schermer, J. A. (2008). A behavioral genetic study of trait emotional intelligence. Emotion, 8, 635-642. 
Walter, F., Cole, M. S., \& Humphrey, R. H. (2011). Emotional intelligence: Sine qua non of leadership or folderol? Academy of Management Perspectives, 25, 45-59.

Wang, G., Seibert, S. E., \& Boles, T. L. (2011). Synthesizing what we know and looking ahead: A meta-analytical review of 30 years of emotional labor research. Research on Emotion in Organizations, 7, $15-43$.

Weber, M. (1968). Economy and Society: An outline of interpretive sociology (3 vols., translated by E. Fischoff et al.). G. Roth and C. Wittich (eds). New York: Bedminster Press.

Whitener, E. M. (1990). Confusion of confidence intervals and credibility intervals in metaanalysis. Journal of Applied Psychology, 75, 315-321. 
Table 1. Psychometric Meta-Analysis Results

\begin{tabular}{|c|c|c|c|c|c|c|c|c|c|c|c|c|}
\hline & $k$ & $N$ & $\bar{r}_{O}$ & $S D_{r}$ & $\hat{\rho}$ & $S D_{\rho}$ & CI LL & CI UL & CV LL & CV UL & $\operatorname{Var}_{\text {art }} \%$ & Sig. Diff. \\
\hline EI - OCB & 68 & 16,386 & .43 & .19 & .52 & .21 & .46 & .57 & .24 & .79 & $\mathbf{8 \%}$ & \\
\hline $\begin{array}{c}\text { x. Stream } 1 \text { ability EI } \\
\text { Target of OCB }\end{array}$ & 7 & 1,022 & .13 & .09 & .17 & .00 & .11 & .23 & .17 & .17 & $100 \%$ & $\mathbf{y}, \mathbf{z}$ \\
\hline a. OCB-I & 6 & 937 & .11 & .06 & .14 & .00 & .08 & .21 & .14 & .14 & $100 \%$ & - \\
\hline b. OCB-O & 6 & 937 & .19 & .16 & .24 & .17 & .09 & .40 & .02 & .47 & $24 \%$ & - \\
\hline $\begin{array}{c}\text { y. Stream } 2 \text { self-report EI } \\
\text { Target of OCB }\end{array}$ & 37 & 9,427 & .47 & .18 & .57 & .20 & .50 & .63 & .32 & .82 & $8 \%$ & $\mathbf{x}$ \\
\hline a. OCB-I & 17 & 3,398 & .40 & .14 & .51 & .15 & .44 & .59 & .33 & .70 & $21 \%$ & - \\
\hline b. OCB-O & 15 & 2,562 & .36 & .17 & .48 & .21 & .37 & .59 & .21 & .75 & $15 \%$ & - \\
\hline OCB Rating Method & & & & & & & & & & & & \\
\hline a. Self-Report & 27 & 6,463 & .51 & .16 & .60 & .17 & .53 & .66 & .38 & .82 & $10 \%$ & - \\
\hline $\begin{array}{l}\text { b. Observer-Report } \\
\text { Industry }\end{array}$ & 10 & 2,964 & .41 & .19 & .50 & .23 & .36 & .64 & .21 & .79 & $6 \%$ & - \\
\hline a. Health Care and Service & 13 & 3,249 & .54 & .14 & .62 & .13 & .55 & .70 & .46 & .79 & $14 \%$ & $\mathrm{~b}$ \\
\hline b. Others & 19 & 4,800 & .42 & .19 & .51 & .21 & .41 & .61 & .24 & .79 & $8 \%$ & $\mathrm{a}$ \\
\hline Stream 2 EI Scale & & & & & & & & & & & & \\
\hline a. WLEIS & 16 & 5,276 & .45 & .19 & .53 & .21 & .42 & .63 & .26 & .80 & $6 \%$ & - \\
\hline b. EIS & 17 & 3,531 & .52 & .16 & .62 & .16 & .54 & .70 & .42 & .82 & $13 \%$ & - \\
\hline OCB Scale & & & & & & & & & & & & \\
\hline a. Podsakoff et al. & 6 & 1,764 & .57 & .17 & .66 & .17 & .52 & .80 & .44 & .88 & $7 \%$ & $\mathrm{c}$ \\
\hline b. $V \& M$ & 2 & 1,027 & .50 & .15 & .61 & .18 & .35 & .86 & .38 & .84 & $5 \%$ & - \\
\hline c. Smith et al. & 4 & 945 & .31 & .22 & .43 & .28 & .15 & .71 & .07 & .78 & $8 \%$ & $\mathrm{a}, \mathrm{d}$ \\
\hline d. W \& A & 2 & 464 & .62 & .00 & .73 & .00 & .67 & .78 & .73 & .73 & $100 \%$ & $\mathrm{c}, \mathrm{e}$ \\
\hline e. Others & 21 & 4,779 & .46 & .16 & .54 & .17 & .46 & .61 & .32 & .76 & $12 \%$ & $\mathrm{~d}$ \\
\hline Publication Status & & & & & & & & & & & & \\
\hline a. Published & 27 & 7,136 & .50 & .15 & .60 & .17 & .53 & .66 & .38 & .81 & $9 \%$ & - \\
\hline b. Unpublished & 10 & 2,291 & .38 & .22 & .48 & .24 & .32 & .63 & .17 & .78 & $8 \%$ & - \\
\hline $\begin{array}{l}\text { z. Stream } 3 \text { mixed } \\
\text { competency EI } \\
\text { Target of OCB }\end{array}$ & 24 & 5,937 & .41 & .16 & .48 & .20 & .40 & .57 & .23 & .74 & $9 \%$ & $\mathbf{x}$ \\
\hline a. OCB-I & 8 & 2,169 & .40 & .19 & .50 & .25 & .32 & .67 & .18 & .82 & $6 \%$ & - \\
\hline
\end{tabular}




\begin{tabular}{|c|c|c|c|c|c|c|c|c|c|c|c|c|}
\hline b. OCB-O & 7 & 1,912 & .47 & .22 & .59 & .29 & .37 & .81 & .21 & .96 & $4 \%$ & - \\
\hline \multicolumn{13}{|l|}{ OCB Rating Method } \\
\hline a. Self-Report & 22 & 5,574 & .40 & .17 & .48 & .21 & .39 & .57 & .21 & .74 & $9 \%$ & - \\
\hline $\begin{array}{l}\text { b. Observer-Report } \\
\text { Industry }\end{array}$ & 2 & 363 & .46 & .07 & .57 & .05 & .46 & .69 & .50 & .64 & $64 \%$ & - \\
\hline a. Health Care and Service & 9 & 1,955 & .40 & .21 & .49 & .29 & .30 & .68 & .12 & .85 & $6 \%$ & - \\
\hline b. Others & 14 & 3,647 & .41 & .14 & .47 & .16 & .39 & .56 & .27 & .67 & $13 \%$ & - \\
\hline \multicolumn{13}{|l|}{ Stream 3 EI Scale } \\
\hline a. ECI & 5 & 1,086 & .40 & .17 & .48 & .21 & .28 & .67 & .20 & .75 & $10 \%$ & - \\
\hline b. EQ-i & 2 & 492 & .52 & .09 & .65 & .09 & .52 & .79 & .54 & .76 & $31 \%$ & - \\
\hline c. Genos & 4 & 1,269 & .39 & .15 & .46 & .18 & .28 & .64 & .23 & .68 & $9 \%$ & - \\
\hline d. Others & 13 & 3,090 & .40 & .16 & .47 & .21 & .36 & .59 & .21 & .74 & $9 \%$ & - \\
\hline \multicolumn{13}{|l|}{ OCB Scale } \\
\hline a. L\&A & 2 & 616 & .26 & .01 & .28 & .00 & .21 & .36 & .28 & .28 & $100 \%$ & $\mathrm{~b}, \mathrm{c}, \mathrm{e}$ \\
\hline a. Podsakoff et al. & 7 & 2,190 & .40 & .14 & .47 & .18 & .34 & .61 & .25 & .70 & $10 \%$ & $\mathrm{a}$ \\
\hline c. $\mathrm{V} \& \mathrm{M}$ & 2 & 526 & .63 & .19 & .81 & .34 & .33 & 1.28 & .37 & 1.25 & $2 \%$ & $\mathrm{a}$ \\
\hline d. Smith et al. & 2 & 511 & .35 & .21 & .43 & .23 & .10 & .75 & .13 & .72 & $8 \%$ & - \\
\hline e. Others & 10 & 1,869 & .43 & .13 & .52 & .11 & .45 & .60 & .38 & .66 & $31 \%$ & $\mathrm{a}$ \\
\hline \multicolumn{13}{|l|}{ Publication Status } \\
\hline a. Published & 20 & 4,886 & .42 & .17 & .50 & .21 & .41 & .60 & .24 & .77 & $9 \%$ & - \\
\hline b. Unpublished & 4 & 1,051 & .36 & .12 & .40 & .14 & .25 & .55 & .22 & .58 & $16 \%$ & - \\
\hline EI - CWB & 17 & 3,914 & -.28 & .23 & -.34 & .25 & -.46 & -.21 & -.66 & -.02 & $7 \%$ & \\
\hline \multicolumn{13}{|l|}{ Target of CWB } \\
\hline a. CWB-I & 4 & 806 & -.05 & .18 & -.07 & .21 & -.29 & .15 & -.34 & .20 & $16 \%$ & - \\
\hline b. CWB-O & 2 & 454 & .02 & .15 & .04 & .17 & -.22 & .29 & -.18 & .25 & $20 \%$ & - \\
\hline \multicolumn{11}{|l|}{ Target of CWB } & $8 \%$ & $\mathbf{u}$ \\
\hline a. CWB-I & 6 & 1,437 & -.25 & .12 & -.27 & .10 & -.37 & -.18 & -.40 & -.14 & $31 \%$ & - \\
\hline b. CWB-O & 6 & 1,496 & -.33 & .08 & -.36 & .05 & -.42 & -.30 & -.43 & -.29 & $57 \%$ & - \\
\hline \multicolumn{13}{|l|}{ CWB Rating Method } \\
\hline a. Self-Report & 6 & 1,622 & -.39 & .18 & -.45 & .19 & -.60 & -.29 & -.69 & -.21 & $9 \%$ & - \\
\hline b. Observer-Report & 4 & 947 & -.23 & .23 & -.27 & .24 & -.51 & -.02 & -.58 & .05 & $8 \%$ & - \\
\hline
\end{tabular}


Industry

\begin{tabular}{|c|c|c|c|c|c|c|c|c|c|c|c|c|}
\hline a. Health Care and Service & 5 & 1,183 & -.47 & .16 & -.51 & .17 & -.67 & -.35 & -.73 & -.29 & $9 \%$ & b \\
\hline b. Others & 5 & 1,376 & -.22 & .19 & -.26 & .21 & -.45 & -.07 & -.53 & .00 & $10 \%$ & $\mathrm{a}$ \\
\hline \multicolumn{13}{|l|}{ EI Scale } \\
\hline a. WLEIS & 9 & 2,449 & -.34 & .22 & -.39 & .23 & -.55 & -.24 & -.69 & -.10 & $7 \%$ & - \\
\hline b. EIS & 2 & 280 & -.26 & .07 & -.30 & .00 & -.41 & -.19 & -.30 & -.30 & $100 \%$ & - \\
\hline \multicolumn{13}{|l|}{ CWB Scale } \\
\hline a. B\&R & 1 & 429 & -.20 & .00 & -.25 & .00 & -.34 & -.16 & -.25 & -.25 & NA & b \\
\hline b. Spector et al. & 3 & 593 & -.40 & .04 & -.45 & .00 & -.52 & -.38 & -.45 & -.45 & $100 \%$ & $\mathrm{a}$ \\
\hline c. Others & 7 & 1,707 & -.34 & .25 & -.39 & .27 & -.59 & -.19 & -.73 & -.05 & $5 \%$ & - \\
\hline \multicolumn{13}{|l|}{ Publication Status } \\
\hline a. Published & 9 & 2,247 & -.39 & .16 & -.45 & .15 & -.56 & -.34 & -.65 & -.25 & $13 \%$ & $\mathrm{~b}$ \\
\hline b. Unpublished & 2 & 482 & -.05 & .20 & -.07 & .21 & -.37 & .24 & -.34 & .20 & $11 \%$ & $\mathrm{a}$ \\
\hline v. Stream 3 mixed & & & & & & & & & & & & \\
\hline $\begin{array}{l}\text { ompetency EI } \\
\text { Target of CWB }\end{array}$ & 3 & 546 & -.37 & .15 & -.42 & .15 & -.60 & -.24 & -.61 & -.23 & $20 \%$ & $\mathbf{u}$ \\
\hline a. CWB-I & 3 & 239 & -.21 & .23 & -.25 & .27 & -.58 & .07 & -.59 & .09 & $20 \%$ & - \\
\hline b. CWB-O & 2 & 105 & -.36 & .27 & -.41 & .29 & -.85 & .03 & -.78 & -.03 & $19 \%$ & - \\
\hline
\end{tabular}

Note. $k=$ number of independent samples; $N=$ sample size; $\bar{r}_{o}=$ uncorrected sample-size-weighted mean correlation; $S D_{r}=$ sample-size-weighted standard deviation of observed mean correlations; $\hat{\rho}=$ corrected sample-size-weighted mean correlation; $S D_{\rho}=$ sample-size-weighted standard deviation of corrected mean correlations; CI LL and CI UL = lower and upper bounds of corrected 95\% confidence interval; CV LL and CV UL = lower and upper bounds of corrected $80 \%$ credibility interval; $\mathrm{Var}_{\text {art }} \%=$ percent of variance in $\hat{\rho}$ explained by statistical artifacts; Sig. Diff. $=$ significant difference. Letters in this column correspond to the letters in rows and denote that effect sizes are significantly different from one another at .05 level. The sign "-" indicates there is no significant between-group difference. Z-test is performed to assess the statistical significance of between-group difference in effect sizes. $\mathrm{EI}=$ emotional intelligence; $\mathrm{OCB}=$ organizational citizenship behavior; OCB-I = organizational citizenship behavior directed toward individuals; $\mathrm{OCB}-\mathrm{O}=$ organizational citizenship behavior directed toward the organization; $\mathrm{CWB}=$ counterproductive work behavior; CWB-I = counterproductive work behavior directed toward individuals; CWB-O = counterproductive work behavior directed toward the organization; Podsakoff et al. = Podsakoff, MacKenzie, Moorman, and Fetter (1990); V \& M = Van Scotter and Motowidlo (1996); Smith et al. = Smith, Organ, and Near (1983); W \& A = Williams \& Anderson (1991); L \& A = Lee \& Allen (2002); B \& R = Bennett and Robinson (2000); Spector et al. = Spector, Fox, Penney, Bruursema, Goh, and Kessler (2006); EIS = emotional intelligence scale; WLEIS = Wong \& Law emotional intelligence scale; ECI = emotional competence inventory; EQ-i = emotional quotient inventory; Genos = Genos emotional intelligence inventory. 
Table 2. Summary of Results for All Hypotheses

\begin{abstract}
Hypotheses
Hypothesis 1. All three streams of EI ([a]stream 1 ability measures, [b]stream 2 self-reports, and [c]stream 3 mixed models) will be positively related to OCB.

Hypothesis 2. All three streams of EI ([a]stream 1 ability measures, [b]stream 2 self-reports, and [c]stream 3 mixed competency) will be negatively related to CWB.

Hypothesis 3. All three streams of EI ([a]stream 1 ability measures, [b]stream 2 self-reports, and [c]stream 3 mixed models) will show incremental validity and relative importance in predicting OCB when controlling for the Big Five, cognitive intelligence, general self-efficacy, and self-rated job performance.

Hypothesis 4. All three streams of EI ([a]stream 1 ability measures, [b]stream 2 self-reports, and [c]stream 3 mixed models) will show incremental validity and relative importance in predicting CWB when controlling for the Big Five, cognitive intelligence, general self-efficacy, and self-rated job performance.

Hypothesis 5. Stream 3 mixed models will show the strongest positive relationships with OCB, stream 2 self-reports the second strongest, and stream 1 ability models will show the weakest relationships.
\end{abstract}

Hypothesis 6. Stream 3 mixed models will show the strongest negative relationships with CWB, stream 2 self-reports the second strongest, and stream 1 ability models will show the weakest relationships.

Hypothesis 7. The relationships are stronger in healthcare and service industries than in other industries (a) between stream 2 self-reports and OCB, (b) between stream 3 mixed models and OCB, and (c) between stream 2 self-reports and CWB.

Hypothesis 8 . The relationships will become weaker when observer ratings of OCB and CWB are used (a) between stream 2 self-reports and OCB, (b) between stream 3 mixed models and OCB, and (c) between stream 2 self-reports and CWB.

Research Question 1. Do the relationships (a) between stream 2 self-reports and OCB and (b) between stream 3 mixed models and OCB and (c) between stream 2 self-reports and CWB vary across different measures of EI, OCB, and CWB?

Research Question 2. Do the relationships between all three streams of EI and OCB and all three streams of EI and CWB vary by the target (individual vs. organizational) of the behavior?

\section{Results}

Supported.

Hypotheses 2(b) and 2(c) were supported.

Hypotheses 3(b) and 3(c) were supported in incremental validity tests. Hypotheses 3(a), (b), and (c) were supported in relative weight analyses. Hypotheses 4(b) and 4(c) were supported in incremental validity tests. Hypotheses 4(a), (b), and (c) were supported in relative weight analyses. Partially supported because stream 2 self-reports and stream 3 mixed models do not differ, although stream 1 ability shows the weakest relationship.

Partially supported because stream 2 self-reports and stream 3 mixed models do not differ, although stream 1 ability shows the weakest relationship.

Hypotheses 7(a) and 7(c) were supported.

Not supported.

Relationships do not vary across EI measures (within streams) but vary across OCB and CWB measures.

Relationships do not vary by the target of OCB and CWB. 
Table 3. Hierarchical Multiple Regression and Relative Weight Analyses for All Three Streams of EI in Predicting OCB

\begin{tabular}{|c|c|c|c|c|c|c|c|c|c|c|c|c|}
\hline & \multicolumn{3}{|c|}{ Model 1} & \multicolumn{3}{|c|}{ Model 2} & \multicolumn{3}{|c|}{ Model 3} & \multicolumn{3}{|c|}{ Model 4} \\
\hline & $\beta$ & RW & RW\% & $\beta$ & RW & RW\% & $\beta$ & RW & RW\% & $\beta$ & RW & RW\% \\
\hline Cognitive Ability & $.21^{* * * *}$ & .049 & $32.2 \%$ & $.21^{* * * *}$ & .045 & $29.4 \%$ & $.20^{* * * *}$ & .043 & $13.0 \%$ & $.29^{* * * *}$ & .052 & $8.5 \%$ \\
\hline Neuroticism & $.16^{* * * *}$ & .005 & $3.5 \%$ & $.17^{* * *}$ & .005 & $3.3 \%$ & $.22^{* * * *}$ & .009 & $2.7 \%$ & $.67^{* * *}$ & .050 & $8.1 \%$ \\
\hline Extraversion & $-.14^{* * *}$ & .005 & $3.1 \%$ & $-.15^{* * *}$ & .005 & $2.9 \%$ & $-.15^{* * *}$ & .005 & $1.6 \%$ & $-.62^{* * * *}$ & .043 & $7.0 \%$ \\
\hline Openness & $.09^{* * *}$ & .009 & $5.9 \%$ & $.10^{* * * *}$ & .008 & $5.5 \%$ & .01 & .006 & $2.0 \%$ & $.05^{* *}$ & .014 & $2.3 \%$ \\
\hline Agreeableness & $.14^{* * *}$ & .011 & $7.4 \%$ & $.16^{* * *}$ & .010 & $6.5 \%$ & $.13^{* * *}$ & .009 & $2.7 \%$ & $.31^{* * *}$ & .017 & $2.8 \%$ \\
\hline Conscientiousness & $.04^{*}$ & .014 & $8.9 \%$ & .04 & .013 & $8.7 \%$ & .00 & .011 & $3.4 \%$ & $-.15^{* * *}$ & .017 & $2.7 \%$ \\
\hline GSE & $.34^{* * *}$ & .045 & $29.3 \%$ & $.37^{* * *}$ & .039 & $25.6 \%$ & $.20^{* * *}$ & .029 & $8.9 \%$ & $.83^{* * *}$ & .068 & $11.0 \%$ \\
\hline Self-rated job performance & .02 & .015 & $9.8 \%$ & .00 & .016 & $10.2 \%$ & $-.16^{* * *}$ & .015 & $4.6 \%$ & $-.39^{* * *}$ & .018 & $2.9 \%$ \\
\hline Stream 1 ability EI & & & & -.03 & .012 & $7.9 \%$ & -.00 & .012 & $3.7 \%$ & $-.36^{* * *}$ & .010 & $1.6 \%$ \\
\hline Stream 2 self-report EI & & & & & & & $.55^{* * *}$ & .189 & $57.4 \%$ & & & \\
\hline Stream 3 mixed competency EI & & & & & & & & & & $1.03^{* * *}$ & .328 & $53.2 \%$ \\
\hline$R^{2}$ & $.15^{* * *}$ & & & $.15^{* * *}$ & & & $.33^{* * *}$ & & & $.62^{* * * *}$ & & \\
\hline$\Delta R^{2}$ & & & & .00 & & & $.18^{* * *}$ & & & $.47^{* * *}$ & & \\
\hline$N_{\text {harmonic }}$ & 3,291 & & & 2,256 & & & 2,398 & & & 2,157 & & \\
\hline
\end{tabular}

Note. $N_{\text {harmonic }}=$ harmonic mean sample size; $\beta=$ standardized regression weights; RW = relative weight; RW\% $=$ percent of relative weight (computed by dividing individual relative weight by the sum of individual relative weight and multiplying by 100); $R^{2}=$ multiple correlations; $\Delta R^{2}=$ incremental change in $R^{2}$; $\mathrm{EI}=$ emotional intelligence; $\mathrm{OCB}=$ organizational citizenship behavior; GSE = general self-efficacy. In terms of the computation of $\Delta R^{2}$, Model 2 was compared to Model 1. Model 3 and Model 4 were compared to Model 2. Observer-reported OCB was used.

${ }^{*} p<.05$

${ }_{* * * *}^{* *}<.01$

${ }^{* *} p<.001$ 
Table 4. Hierarchical Multiple Regression and Relative Weight Analyses for All Three Streams of EI in Predicting CWB

\begin{tabular}{|c|c|c|c|c|c|c|c|c|c|c|c|c|}
\hline & \multicolumn{3}{|c|}{ Model 1} & \multicolumn{3}{|c|}{ Model 2} & \multicolumn{3}{|c|}{ Model 3} & \multicolumn{3}{|c|}{ Model 4} \\
\hline & $\beta$ & RW & RW\% & $\beta$ & RW & RW\% & $\beta$ & RW & RW\% & $\beta$ & RW & RW\% \\
\hline Cognitive Ability & $-.07^{* * *}$ & .009 & $5.5 \%$ & $-.08^{* * *}$ & .008 & $4.6 \%$ & $-.07^{* * *}$ & .007 & $3.5 \%$ & $-.14^{* * * *}$ & .010 & $2.0 \%$ \\
\hline Neuroticism & $-.27^{* * * *}$ & .011 & $6.8 \%$ & $-.29^{* * * *}$ & .011 & $6.6 \%$ & $-.31^{* * * *}$ & .013 & $6.5 \%$ & $-.71^{* * * *}$ & .051 & $10.6 \%$ \\
\hline Extraversion & $.34^{* * *}$ & .025 & $15.3 \%$ & $.36^{* * *}$ & .024 & $14.9 \%$ & $.36^{* * *}$ & .026 & $12.8 \%$ & $.75^{* * *}$ & .072 & $15.0 \%$ \\
\hline Openness & $-.21^{* * *}$ & .019 & $11.9 \%$ & $-.22^{* * *}$ & .018 & $11.2 \%$ & $-.18^{* * *}$ & .015 & $7.2 \%$ & $-.18^{* * *}$ & .018 & $3.8 \%$ \\
\hline Agreeableness & $-.32^{* * *}$ & .048 & $29.5 \%$ & $-.35^{* * *}$ & .044 & $27.0 \%$ & $-.33^{* * *}$ & .042 & $20.6 \%$ & $-.47^{* * *}$ & .049 & $10.1 \%$ \\
\hline Conscientiousness & -.05 & .017 & $10.4 \%$ & -.04 & .017 & $10.2 \%$ & -.03 & .014 & $7.0 \%$ & $.11^{* * * *}$ & .016 & $3.4 \%$ \\
\hline GSE & $-.39^{* * *}$ & .028 & $17.2 \%$ & $-.43^{* * *}$ & .024 & $14.8 \%$ & $-.36^{* * * *}$ & .019 & $9.4 \%$ & $-.81^{* * * *}$ & .045 & $9.3 \%$ \\
\hline Self-rated job performance & $.08^{* *}$ & .005 & $3.3 \%$ & $.10^{* *}$ & .006 & $3.4 \%$ & $.18^{* * *}$ & .006 & $2.7 \%$ & $.43^{* * *}$ & .013 & $2.6 \%$ \\
\hline Stream 1 ability EI & & & & .05 & .012 & $7.3 \%$ & .04 & .012 & $5.9 \%$ & $.33^{* * *}$ & .007 & $1.5 \%$ \\
\hline Stream 2 self-report EI & & & & & & & $-.26^{* * *}$ & .049 & $24.4 \%$ & & & \\
\hline Stream 3 mixed competency EI & & & & & & & & & & $-.85^{* * *}$ & .201 & $41.6 \%$ \\
\hline$R^{2}$ & $.16^{* * *}$ & & & $.16^{* * *}$ & & & $.20^{* * *}$ & & & $.48^{* * *}$ & & \\
\hline$\Delta R^{2}$ & & & & .00 & & & $.04^{* * * *}$ & & & $.32^{* * * *}$ & & \\
\hline$N_{\text {harmonic }}$ & 1,582 & & & 1,382 & & & 1,517 & & & 1,479 & & \\
\hline
\end{tabular}

Note. $N_{\text {harmonic }}=$ harmonic mean sample size; $\beta=$ standardized regression weights; $\mathrm{RW}=$ relative weight; RW\% $=$ percent of relative weight (computed by dividing individual relative weight by the sum of individual relative weight and multiplying by 100 ); $R^{2}=$ multiple correlations; $\Delta R^{2}=$ incremental change in $R^{2}$; $\mathrm{EI}=$ emotional intelligence; $\mathrm{CWB}=$ counterproductive work behavior; GSE = general self-efficacy. In terms of the computation of $\Delta R^{2}$, Model 2 was compared to Model 1. Model 3 and Model 4 were compared to Model 2. Observer-reported CWB was used. Our systematic search did not identify any studies used stream 3 mixed competency EI to predict observer-reported CWB. Thus, we used corrected correlation between stream 3 mixed competency EI and self-reported CWB to impute this missing cell in the input correlation matrix. We argued that this method of imputation is reasonable. Berry et al. (2012) performed a meta-analysis and found that self- and observer-reported CWB have fairly high convergence and demonstrate very similar patterns and sizes of relations with a set of common correlates. Berry et al. recommended the use of self-reported CWB as a viable alternative to observer-reported CWB.

${ }^{* * *}<.01$

${ }^{* * *} p<.001$ 